\title{
Analysis of hearing improvement in the patients operated on due to otosclerosis in the Otolaryngology Department of Jagiellonian University of Cracow, Poland
}

Wkład autorów:

A-Projekt badań

B-Zbieranie danych

C-Analiza statystyczna

-Interpretacja danych

E-Przygotowanie manuskryptu

F-Analiza literatury

G-Zbieranie funduszy

\author{
Maciej Wiatr ${ }^{\mathrm{ABC}}$, Renata Cawlik ${ }^{\mathrm{DF}}$, Aleksandra Boroń ${ }^{\mathrm{BDEC}}$, Agnieszka Wiatr ${ }^{\mathrm{CD}}$, \\ Jacek Składzień ${ }^{\mathrm{CDF}}$ \\ Jagiellonian University Otolaryngology Department, Crakow, Poland
}

Article history: Received:28.01.2016 Accepted: 04.05.2016 Published: 15.06.2016

ABSTRACT: $\quad$ Background: Otosclerosis is the most common cause of condactive hearing loss between 15 and 50 years old. The most common symptoms are hearinglosss and tinnitus. Surgery is currently the preferred treatment method.

Aim: The aim of our study was to analyze the outcomes of patients treated surgically due to otosclerosis in terms of the observed changes in pure tone audiometry and speech audiometry

Material and methods: We observated 300 patients operated on middle ear for the fist time in the Department of Otolarygology at the Jagiellonian University of Cracow from 2010 to 2011. We used a special questinnaire which includes diagnostics of the ear"s disease,pure tone audiometry, speech audiometrii and longterm effects.

Results: We discuss 53 operated ears and analyze changes in pure tone audiometry. We divided patients into 2 groups depending on $100 \%$ speech understanding in speech auodiometry or not.

Conclusion: 1. Lack of $100 \%$ speech understanding in speech audiometry correlated with greater sensorineural hearing loss than in patients who achieved $100 \%$ speech understanding prior to surgery.

2. Lack of $100 \%$ speech understanding in speech audiometry is a predictive factor for worse prognosis in improving hearing in patients operated on for otosclerosis.

3. Reconstruction of the ossicular chain in patients, regardless of the degree of speech understanding, did not produce significant changes in the average values of bone conduction.

KEYWORDS: $\quad$ otosclerosis, otosclerosis - therapy, speech audiometry

\section{INTRODUCTION}

Otosclerosis is a disease of the bony capsule of inner ear that involves bone remodeling processes resulting from the activity of osteoblasts followed by osteoclasts. As a consequence, abnormal ossification occurs leading to disturbed ear function dependent on the location of changes. The disorder is observed only in humans and is the one of the most common causes of conductive hearing loss between 15 and 50 years of age (3). First mentions of the disorder date back to 1735, when an Italian anatomist, Antonio Mario Valsalva of Bologna described immobilization of stapedial plate (1). The term „oto- sclerosis" was used for the first time by German otologist, Anton von Tröltsch (2). The etiology of the disorder has not been fully elucidated or explained. A number of authors consider it to be of multifactorial origin, with genetic susceptibility, hormonal disorders, or viral infections being listed as potential causes (5). Otosclerosis is manifested with tinnitus and hearing loss, initially conductive in nature but later on accompanied by sensorineural component, resulting in mixed hearing loss. The disease occurs bilaterally albeit not simultaneously. According to estimates, otosclerosis will be diagnosed in $0.5 \%$ of general population during their lifetime; however, autopsy examinations reveal that asymptomatic ossification foci with- 
in the temporal bone occur in as many as $10 \%$ of people. To date, no effective method was found for treating sensorineural hearing loss resulting from cochlear ossification. The only effective treatment consists in a surgical procedure to eliminate the conductive component of hearing loss $(7,12)$. Stapedotomy is the treatment of choice. The procedure includes removal of stapedial suprastructure (head and crura) and in creating an orifice in the stapedial plate that had been immobilized in the course of the disease. Continuity of ossicular chain is restored by means of prosthesis mounted to the long process of the incus, its second end consisting of a piston introduced into the orifice inside the stapedial plate. Stapedectomy is rare and results in worse surgical outcomes.

\section{OBJECTIVE}

The objective of the study was to analyze the outcomes in patients subjected to surgical treatment for otosclerosis in terms of the changes observed in pure tone audiometry and speech audiometry.

\section{MATERIAL AND METHOD}

The study was a retrospective analysis of patients undergoing first surgical treatment of otosclerosis surgery at the Department of Otolarygology of the Jagiellonian University Medical College in Cracow in years 2010-2011. In that period, ear surgeries were performed in 300 patients. Included in the study were 50 patients, 26 females and 24 males aged 15 to 63 . The mean age of patients was 42 . The analysis was based on a special questionnaire that included the reported complaints, results of otolaryngological examination, preoperative diagnostic pure tone audiometry and speech audiometry as well as long-term post-operative effects measured six months after the surgical treatment.

\section{RESULTS}

Included in the analysis were 53 successive patients undergoing first surgery for otosclerosis. All patients underwent a stapedectomy procedure. Excluded from the study were patients undergoing resurgeries or stapedectomy procedures. On the basis of the analysis of preoperative audiometric measurements, patients were stratified into two groups depending on whether or not they achieved $100 \%$ speech understanding in speech audiometry.

The primary element that describes the improvement in hearing following surgical treatment is the degree of air-bone gap closure, i. e. the difference between air-and bone conduction thresholds.
Average air bone gap was calculated as arithmetic mean of values for typical speech frequencies $(500,1000,2000$, and 4000 $\mathrm{Hz}$ ). The degree of air-bone gap closure (reduction) in $\mathrm{dB}$ was the measure of postoperative hearing improvement. Similar airbone gap closure of below 50\% was obtained in both groups.

Both study groups (complete (100\%) vs. incomplete $(<100 \%)$ free-field speech discrimination in speech audiometry) had significantly different bone conduction values. Patients who achieved speech understanding of less than 100\% were characterized by a significantly poorer bone conduction threshold amounting to the average of $37.1 \mathrm{db}$ calculated as arithmetic mean of bone conduction at all tested speech frequencies. Slight postoperative improvement $(0.71 \mathrm{~dB}$ on average) was observed in these patients. On the other hand, in the group of patients with $100 \%$ speech discrimination scores in speech audiometric measurements, the mean bone conduction threshold was $24.53 \mathrm{~dB}$ and was reduced to the average of $2.24 \mathrm{~dB}$ after surgery.

Otosclerosis is characterized by the so-called Carhart's sign, i.e. a ca. 10-20 dB slump in bone conduction curve at $2000 \mathrm{~Hz}$. This results from the mechanical immobilization of stapes (44) due to the disturbed natural resonance of the ossicular chain occurring at ca. $2000 \mathrm{~Hz}$. Both groups were characterized by an improvement in this parameter (i.e. an improvement in bone conduction at $2000 \mathrm{~Hz}$ ) as a consequence of restored mobility of ossicular chain. Better improvement (in dB) was observed in the group of patients who received a $100 \%$ score in preoperative speech audiometry tests.

\section{DISCUSSION}

Otosclerosis is an autosomal dominant disorder with incomplete gene penetrance; however, $50 \%$ of all cases develop in a spontaneous manner $(4,8,12)$. Most commonly, it affects individuals between 15 and and 50 years of age while being predominant in female patients. Risk factors include the measles virus, hormonal factors (pregnancy) and autoimmune factors (9). Otosclerosis consists of two phases, namely the active and the inactive phase. Most commonly, the disease occurs in Caucasians, its incidence rate being estimated at 0.3-1 \% (11). In most cases, the disease is bilateral; however, the advancement stage differs in both years (13). Otosclerosis may affect stapedial plate and/or cochlea $(1,9,10)$. The main symptom of otosclerosis consists in conductive hearing loss, mixed hearing loss and, in very rare cases, sensorineural hearing loss. Patients complain of tinnitus, usually in the low-frequency range (1013) and, less commonly, dizziness. In otoscopic examination, the tympanic membrane is usually free of any pathologies and 
tuning fork tests confirm the conductive nature of the hearing loss. Gelle's test confirms stapedial immobilization within the oval window and impedance audiometry reveals an absence or abnormality of stapedius muscle reflex. Conductive or mixed hearing loss is usually confirmed in tonal audiometry. In the early stage of the disorder, one may observe a 10-20 $\mathrm{dB}$ slump in the bone conductivity curve at the frequency of $2000 \mathrm{~Hz}$ (Carhart's sign)(10). Speech audiometry results depended on the stage of the disease. The surgery of stapes is the treatment of choice. Indications for surgery in unilateral hearing loss include air conduction curve being raised by 30 $\mathrm{dB}$; in case of bilateral hearing loss, the worse ear is taken into account. Currently stapedotomy leads to lower rates of complications compared to stapedectomy. Postoperative complications of otosclerosis include deafness, facial nerve paralysis, taste disturbances, tympanic membrane perforation, perilymph discharge and perilymphatic fistula $(9,12,13)$.

The objective of the analysis was to identify speech audiometry as a prognostic factor of post-operative outcomes in otosclerosis treatment. Regardless of the preoperative degree of speech understanding, improvement in hearing manifested as bone-air gap closure of ca. $50 \%$ was observed in all patients following the surgical treatment. Regardless of the preoperative degree of speech understanding, reconstruction of the ossicular chain resulted in no statistically significant changes in average bone conduction levels.

However, better improvement in average bone conduction was obtained at natural ossicular chain resonance frequency (2000 $\mathrm{Hz}$ ) in the group of patients with $100 \%$ speech understanding than in patients with speech discrimination ability of less than $100 \%$ as assessed by speech audiometry. This is an original conclusion.

Over time, otosclerosis leads to mixed hearing loss. This is due to the fact that abnormal ossification foci occur within the entire labyrinth, resulting in sensorineural component being also involved in the hearing loss. The study patients presented at an advanced stage of the disease manifested by elevated bone conduction thresholds and lack of $100 \%$ speech understanding correlated with high impairment of inner ear function (bone conduction level of nearly $40 \mathrm{~dB}$ )

The results were consistent with those obtained by other authors. The involvement of sensorineural component of hearing loss is considered a negative prognostic factor with regard to the potential improvement of hearing following the surgical treatment of otosclerosis. Notably, surgical treatment involving the opening of the inner ear space is burdened with a risk of complications in the form of complete sensorineural deafness. Different sources estimate the incidence of this compli-
Tab. I. Range of air-bone gap closure in the patients with speech audiometry results of $100 \%$ or worse.

\begin{tabular}{|lll|}
\hline & GROUP I & GROUP II \\
\hline Speech audiometry result & $100 \%$ & $<100 \%$ \\
\hline Average air-bone gap closure (in dB) & $16,1 \mathrm{~dB}$ & $19,9 \mathrm{~dB}$ \\
\hline Average air-bone gap closure (in $\%)$ & $45,6 \%$ & $46,82 \%$ \\
\hline
\end{tabular}

Tab. II. Average bone conduction thresholds and their changes after surgical treatment in the study groups.

\begin{tabular}{|c|c|c|}
\hline & GROUPI & GROUPII \\
\hline Speech audiometry result & $100 \%$ & $<100 \%$ \\
\hline $\begin{array}{l}\text { Average bone conduction threshold } \\
\text { before the surgery (in } \mathrm{dB} \text { ) }\end{array}$ & $24,53 \mathrm{~dB}$ & $37,1 \mathrm{~dB}$ \\
\hline $\begin{array}{l}\text { Change in average bone } \\
\text { conduction threshold in } \mathrm{dB}(\%)\end{array}$ & $\begin{array}{l}+2,24 \mathrm{~dB} \\
(+9,13 \%)\end{array}$ & $\begin{array}{l}-0,71 d B \\
(-1,91 \%)\end{array}$ \\
\hline
\end{tabular}

Tab. III. Changes in Carhart's sign after surgical treatment in the study groups.

\begin{tabular}{lll} 
& GROUPI & GROUP II \\
\hline Speech audiometry result & $100 \%$ & $<100 \%$ \\
$\begin{array}{l}\text { Percentage improvement in } \\
\text { bone conduction at } 2000 \mathrm{~Hz} \\
\text { (Carhart's sign) }\end{array}$ & $34,5 \%$ & $28,6 \%$ \\
\hline
\end{tabular}

cation at 1-3\%. In light of the above findings, one should use special caution when approaching the surgery of otosclerosis within the only hearing ear despite the evident efficacy of surgical treatment.

\section{CONCLUSIONS}

- The lack of $100 \%$ speech understanding in speech audiometry is a negative prognostic factor with regard to the potential improvement in hearing in patients operated on for otosclerosis.

- The lack of $100 \%$ speech understanding in speech audiometry correlates with a higher sensorineural component of hearing loss than that observed in patients with $100 \%$ understanding of speech.

- Regardless of the preoperative degree of speech understanding, reconstruction of the ossicular chain resulted in statistically significant changes in average bone conduction levels.

- Better improvement in average bone conduction was obtained at natural ossicular chain resonance frequency (Carhart's sign) in the group of patients with 100\% speech understanding than in patients with speech discrimination ability of less than $100 \%$. 


\section{REFERENCES}

1. Cureoglu S.: Cochlear Otosclerosis.Curr. Opin. Otolaryngol. Head Neck Surg; 2010; 18 (5): 357-362.

2. Bernardo M. T.: Long term outcome of otosclerosis surgery. Braz. J. Otorhinolaryngol. 2012; 78 (4): $115-119$.

3. Saki N.: Evaluation of Hearing Results in Otosclerotic Patients after Stapedectomy. Iranian Journal of Otorhinolaryngology. No. 4, Vol. 23, Serial No. 65; Autumn 2011.

4. Mahafza1 T.: Surgical Treatment of Otosclerosis: Eight years' Experience at the Jordan University Hospital. Iranian Journal of Otorhinolaryngology. 2015 , (4) 73.

5. Al- Husban H.: Outcome of Management of Otosclerosis by Stapedotomy Compared to Stapedectomy in a Jordanian Population. Oman Medical Journal (2013). Vol. 28, No. 1:36-38 DOI 10.5001/omj.2013.08.

6. Luiz Ataide A.: Audiometric evaluation after stapedotomy with Fisch titanium prosthesis. Braz. J. Otorhinolaryngol. 2013 ; 79 (3): $325-335$.

7. Kolo E.S.: Hearing results in adults after stapedotomy. Nigerian Medical Journal. 2013, 54,4

8. Singh P. P.: Transient Evoked and Distortion Product Otoacoustic Emission Profile in Patients of Otosclerosis: A Preliminary Report. Indian J. Otolaryngol. Head Neck Surg. January-March 2012; 64 (1): 25-30. DOI 10.1007/s12070-011-0148-3.

9. Antonelli P.J.: Early post laser stapedotomy hearing treshold. Am. J. Otol. 1998; 19 (4): 443-446.

10. Hannley M.T.: Audiologic chorocteristicof tehe patient with otosclerosis. Otolaryngol. Clin. North Am. 1993 ; $26: 373-387$.

11. Hall J.G.: Otosklerosis in Norway. A georaphical and genetical study. Acta Otolaryngol. 1974; 324; 1-20.

12. Donnell G.N.: Medical genetics for otolaryngologist. Laryngoscope. 1980; 90: 40-46.

13. Emmett J.R.: Physical examination and clinical evaluationof the patient with otosclerosis. Otolaryngol. Clin. North Am. 1993 ; $26 ; 353-357$.

Word count: 2000 Tables: 3 Figures:- References: 13

Access the article online: DOI: 10.5604/00306657.1202779 Full-text PDF: www.otolaryngologypl.com/fulltxt.php?ICID=1202779

Corresponding author: Maciej Wiatr; Jagiellonian University Otolaryngology Department, Crakow, Poland; e-mail: mwiatr@mp.pl

Copyright (c) 2016 Polish Society of Otorhinolaryngologists Head and Neck Surgeons. Published by Index Copernicus Sp. z o.o. All rights reserved.

Competing interests: The authors declare that they have no competing interests.

Cite this article as: Wiatr M., Gawlik R., Boroń A., Wiatr A., Składzień ].: Analysis of hearing improvement in the patients operated on due to otosclerosis in the Otolaryngology

Department of Jagiellonian University of Cracow, Poland; Otolaryngol Pol 2016; 70 (3): 27-30 